\title{
Tumor Results Standard Unit
}

National Cancer Institute

\section{Source}

National Cancer Institute. Tumor Results Standard Unit. NCI Thesaurus. Code C117425.

The standard unit of measure for the tumor results. 